\title{
Formability of Tailor-Welded Blanks from Dual-Phase and Bake-Hardened Steels with a Planar Anisotropy Influence
}

\author{
A. Schrek, ${ }^{1}$ P. Švec, ${ }^{2}$ and A. Brusilová ${ }^{3}$ \\ Faculty of Mechanical Engineering, Slovak University of Technology in Bratislava, Bratislava, \\ Slovakia \\ 1 alexander.schrek@stuba.sk \\ 2 pavol.svec@stuba.sk \\ 3 alena.brusilova@stuba.sk
}

The formability of two types of tailor-welded blanks was analyzed with the concentration on the effects of planar anisotropy on eras forming of deep-drawn parts. The first tailor-welded blank consisted of bake-hardened BH220 steel with different rolling directions, which is applied to the surface car body parts. The second one consisted of dual-phase DP600 steel with different rolling directions, which is applied to supporting parts of automobiles. Stress-strain characteristics of experimental steel sheets were measured using the tensile tests and used in the respective simulations. Simulations via the Dynaform software were compared to the experimental values measured during the deep-drawing process of rectangular boxes.

Keywords: tailor-welded blanks, deep-drawing, planar anisotropy, rolling texture.

Introduction. Tailor-welded blanks (TWB), which were developed mainly for automotive applications, usually consist of materials with different stress strain properties, different thicknesses or different coatings [1-4]. Using of various steels in TWBs design enables to achieve the different stress strain characteristic in certain sections of the drawn parts. TWBs made of high strength steel and deep-drawing steel sheets have been used for car body parts because they meet the requirements on the strength, stiffness and safety of these parts [4-6].

The weldability and the formability are very important properties of TWBs. The steel sheets used in TWBs are often joined by laser welding which enable minimal deformation of TWBs because of the small heat-affected zones together with high welding speed and large flexibility [7-9]. Deep-drawing process of TWBs consisting of materials with the different mechanical properties is accompanied by non-uniform plastic flaw and weld line movement $[10,11]$. These effects are mainly remarkable at sheets with different thickness or different plastic characteristics, but they were also observed in TWBs consisting of sheets of the identical material and the same thickness but having different deformation textures produced during their rolling process [10-13]. The effect of planar anisotropy on earing of deep drawn-parts with the rectangular box geometries were evaluated using both simulations via the Dynaform software and the deep-drawing experiments.

Experimental Procedure. Dual-phase DP600 and bake-hardened BH220 steel sheets were chosen for the analysis of the effect of planar anisotropy on ear-like deformation of deep-drawn parts made of TWBs. The particular TWBs consisted of the same material (DP600 or BH220 steel) and had the identical thickness of $1.2 \mathrm{~mm}$. However, the orientation of the deformation texture of sheets to the weld line used in the TWB design was different. The sheets of TWBs were welded by the IPG YLR 4500 fiber laser with the maximal power of $4.5 \mathrm{~kW}$ and wave length of $1060 \mathrm{~nm}$. The butt joints with no filler metal were prepared at the beam power of $600 \mathrm{~W}$ and welding speed of $5 \mathrm{~mm} / \mathrm{s}$. To clarify the effect of the deformation texture on the formability of steels under study, the stress-strain characteristics of experimental steel sheets were measured in the rolling direction of 0,45 , 
and $90^{\circ}$. These measurements were used to construct the material models for the simulation of deep-drawing process including flow curves and planar anisotropy.

The chemical composition of experimental steels is given in Tables 1 and 2 and their mechanical properties are summarized in Table 3. The DP600 dual-phase steel has a higher amount of alloying elements, as compared to $\mathrm{BH} 220$ bake-hardened steel. The $\mathrm{BH} 220$ steel has a lower strength and excellent plasticity, which are lucrative for the production of surface car body parts. The higher-strength DP600 steel can be used for the fabrication production of surface car body parts.

T a b 1 e 1

Maximal Concentration (wt.\%) of Elements in the BH220 Steel

\begin{tabular}{|c|c|c|c|c|c|c|c|c||}
\hline Steel & $\mathrm{C}$ & $\mathrm{Si}$ & $\mathrm{Mn}$ & $\mathrm{P}$ & $\mathrm{S}$ & $\mathrm{Al}$ & $\mathrm{Nb}$ & $\mathrm{Ti}$ \\
\hline BH220 & 0.1 & 0.5 & 0.7 & 0.08 & 0.025 & 0.1 & 0.09 & 0.12 \\
\hline
\end{tabular}

$\mathrm{T}$ a b 1 e 2

Maximal Concentration (wt.\%) of Elements in the DP600 Steel

\begin{tabular}{||c|c|c|c|c|c|c|c|c|c|c||}
\hline Steel & $\mathrm{C}$ & $\mathrm{Si}$ & $\mathrm{Mn}$ & $\mathrm{P}$ & $\mathrm{S}$ & $\mathrm{Al}$ & $\mathrm{V}$ & $\mathrm{B}$ & $\mathrm{Cr}+\mathrm{Mo}$ & $\mathrm{Nb}+\mathrm{Ti}$ \\
\hline DP600 & 0.17 & 0.8 & 2.2 & 0.08 & 0.015 & 2.0 & 0.2 & 0.005 & 1.0 & 0.15 \\
\hline
\end{tabular}

T a b 1 e 3

Mechanical Properties of the BH and DP Steels

\begin{tabular}{|c|c|c|c||}
\hline Steel & Tensile strength $(\mathrm{MPa})$ & Yield strength $(\mathrm{MPa})$ & Elongation (\%) \\
\hline BH220 & 400 & 280 & 32 \\
\hline DP600 & 600 & 420 & 20 \\
\hline
\end{tabular}

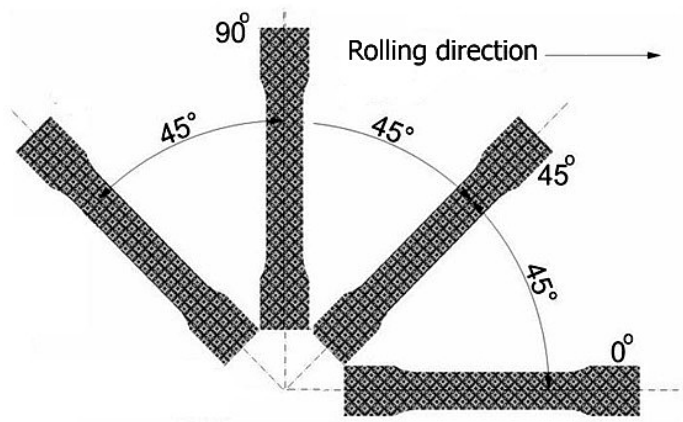

Fig. 1. Specimenss for tensile tests in different rolling directions.

Results and Discussion. Tensile specimens with rolling directions of 0,45 , and $90^{\circ}$ designed for measurement of stress-strain characteristics of experimental steels with a deposited circle grid are depicted in Fig. 1. The specimenss were tested using an Instron 1195 universal testing machine with a crosshead speed of $10 \mathrm{~mm} / \mathrm{min}$. The flow curves constructed for the selected rolling directions are plotted in Figs. 2 and 3 for BH220 and DP600 steels, respectively. The calculated values were 1.551 for rolling direction of $0^{\circ}$, 1.126 for rolling direction of $45^{\circ}$, and 1.873 for rolling direction of $90^{\circ}$, in case of the BH220 steel. For the DP600 steel, these parameters were $0.750,0.881$, and 0.862 for 


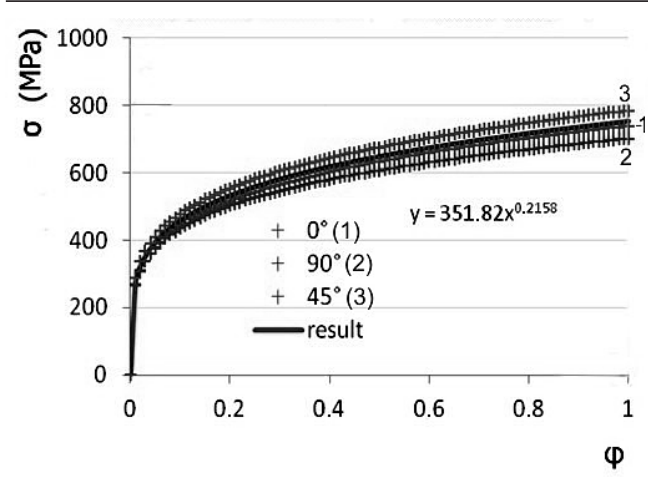

Fig. 2

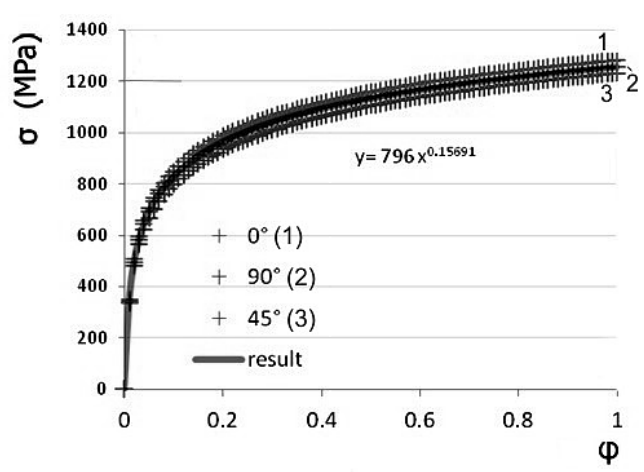

Fig. 3

Fig. 2. The flow curves of $\mathrm{BH} 220$ steel for different rolling directions.

Fig. 3. The flow curves of DP600 steel for different rolling directions.

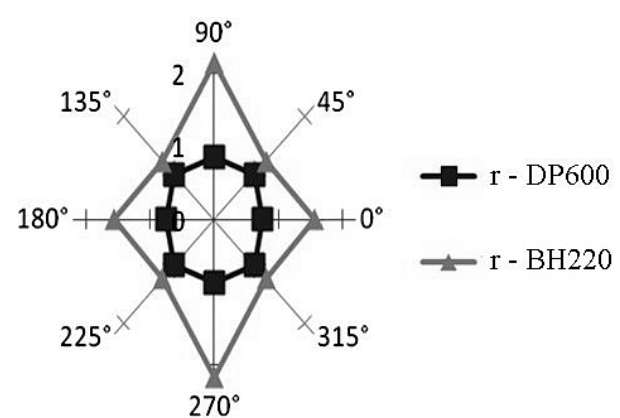

Fig. 4

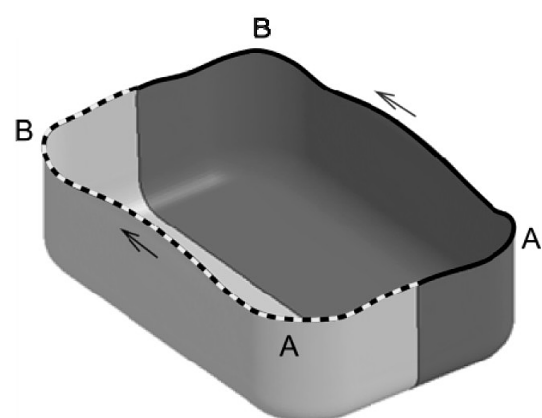

Fig. 5

Fig. 4. Comparison of planar anisotropy values of BH220 and DP600 steels in the polar image.

Fig. 5. Measured heights of the deep-drawn parts' ears.

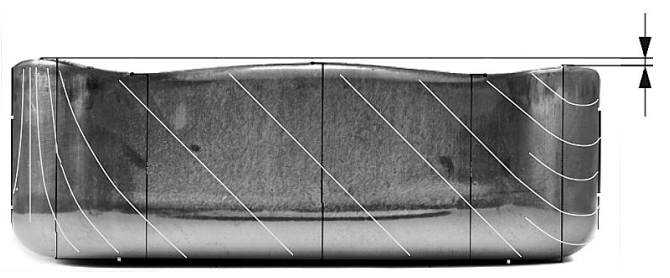

Fig. 6. Deep-drawn part with marked rolling direction.

rolling direction of $0^{\circ}, 45^{\circ}$, and $90^{\circ}$, respectively. The values of planar anisotropy of both experimental steels are compared in Fig. 4. The values obtained from tensile tests were incorporated into the Dynafrom software to realize the simulations.

Welded blanks were deep-drawn in the experimental deep-drawing tool using an PYE160S hydraulic press with a uniform blank holder pressure distribution. At the beginning of the deep-drawing process, the pressure was $4 \mathrm{MPa}$, in case of the $\mathrm{BH} 220$ steel, and $7 \mathrm{MPa}$, in case of the DP600 steel. The drawing speed was $20 \mathrm{~mm} / \mathrm{s}$ for both steels. To minimize the friction between the contact surfaces, an Weodolit N22-3N lubricant was used. The deep-drawn parts had a rectangular geometry with dimensions of $120 \times 80 \times 40 \mathrm{~mm}$, and their geometry was optimized using the Dynaform software.

The planar anisotropy of experimental sheets caused the ear formation in deep-drawn parts as can be seen in Fig. 5. The method of ear height measurement is illustrated in Fig. 6. 


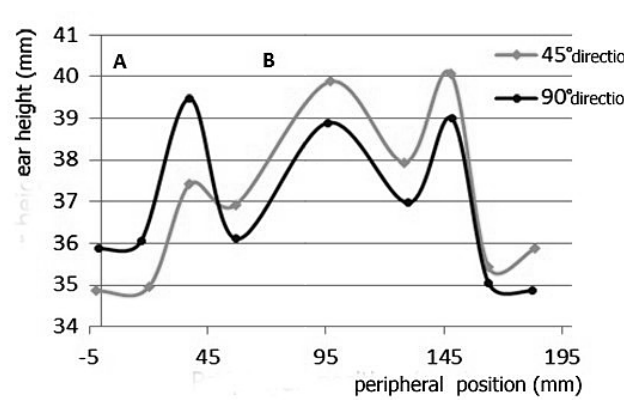

Fig. 7

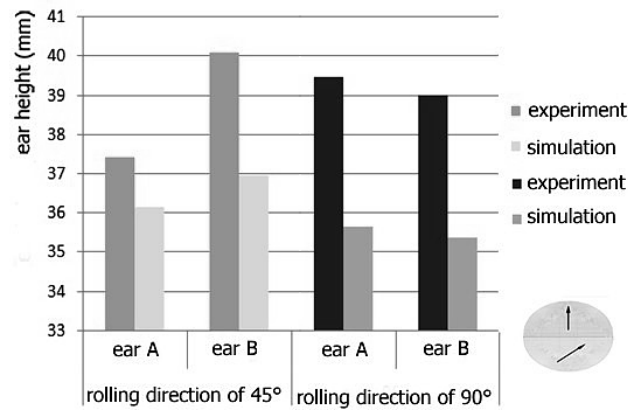

Fig. 8

Fig. 7. Ear heights on the deep-drawn part made of BH220 steel sheets with rolling directions of 45 and $90^{\circ}$.

Fig. 8. Comparison of simulated and experimental A and B ear heights on the deep-drawn part of BH220 steel sheets with rolling directions of 45 and $90^{\circ}$.

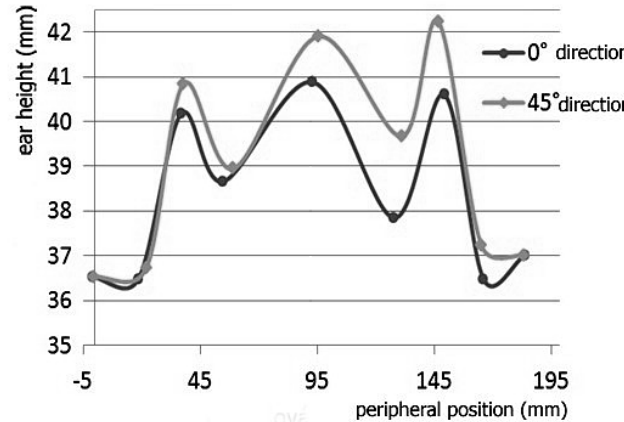

Fig. 9

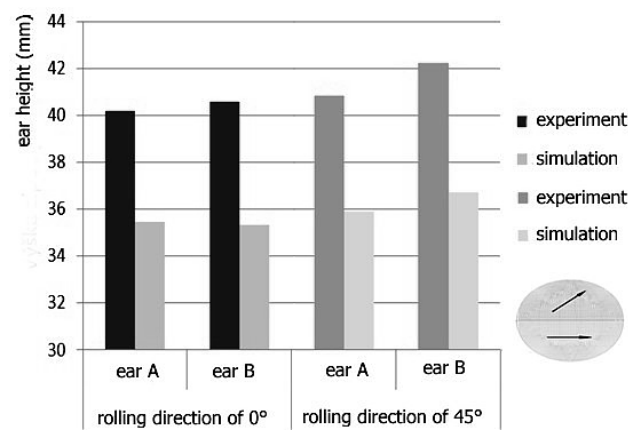

Fig. 10

Fig. 9. Ear heights on the deep-drawn part made of DP600 steel sheets with rolling directions of 0 and $45^{\circ}$

Fig. 10. Comparison of of simulated and experimental A and B ear heights on the deep-drawn part of DP600 steel sheets with rolling directions of 0 and $45^{\circ}$.

The most significant ear formation was observed in case of TWBs made of sheets with rolling directions of 0 and $45^{\circ}$ in respect to the weld line position for both experimental steel sheets.

The progress of $\mathrm{A}$ and $\mathrm{B}$ ear heights representing the hights of the ears in the corners of rectangular deep-drawn part (see Fig. 5) made of TWB consisting of BH220 steel sheets with rolling directions of 90 and $45^{\circ}$ is depicted in Fig. 7. The comparison of these A and B ear heights achieved from simulation and from experiment measured on the deep-drawn part made of BH220 steel sheets with rolling directions of 45 and $90^{\circ}$ is in Fig. 8. The progress of ear hights measured on the deep-drawn part made of TWB consisting of DP600 steel sheets with rolling directions of 0 and $45^{\circ}$ is documented in Fig. 9. The simulated and experiment values of A and B ear heights on the deep-drawn part made of DP600 steel sheets with rolling directions of 0 and $45^{\circ}$ from are compared in Fig. 10. The significant differences between points $\mathrm{A}$ and $\mathrm{B}$ were found in the parts consisting of sheets with rolling directions of 45 and $90^{\circ}$ or 45 and $0^{\circ}$, in case of both experimental steel sheets. The differences between points $\mathrm{A}$ and $\mathrm{B}$ in deep-drawn parts consisting of sheets with rolling directions of 0 or $90^{\circ}$ were minimal. The simulated heights of all ears were smaller than the experimental ones but the differences between the ears were similar (see Figs. 8 and 10). 
Conclusions. The planar anisotropy is shown to cause the significant asymmetry of the plastic flow in TWBs and influence the final geometry of deep-drawn parts. Using the TWBs consisting of sheets with rolling directions of $45^{\circ}$ to the weld line is the most critical. The heights of ears in the corners of deep-drawn parts are relatively constant in TWBs consisting of sheets with rolling directions of 0 or $90^{\circ}$. In case the sheets used in TWBs have the rolling direction of $45^{\circ}$, the additional asymmetry appears, and heights of developed ears become non-uniform. The effect of planar anisotropy on the ear formation is less sensible for the DP600 steel, in comparison to BH220 one. The smaller-scale ear formation in the DP600 steel, as comapred to BH220 one, was confirmed by simulations and experimental results. The application of accurate material models in this sudy made it possible to obtain the comparable simulated and experimental results.

Acknowledgments. This work was supported by the Slovak Research and Development Agency under the contract No. APVV-0281-12.

1. M. Merklein, M. Johannes, M. Lechner, and A. Kuppert, "A review on tailored blanks Production, applications and evaluation," J. Mater. Process. Tech., 214, 151-164 (2014).

2. E. Evin and M. Tomas, "Comparison of deformation properties of steel sheets for car body parts," Procedia Engineer., 48, 115-122 (2012).

3. P. Bałon, A. Świątoniowski, and J. Szostak, "Improved method of springback compensation in metal forming analysis," Strength Mater., 48, No. 4, 540-550 (2016).

4. B. Kinsey and X. Wu, Tailor Welded Blanks for Advanced Manufacturing, Woodhead Publishing, Cambridge (2011).

5. J. Bílik, J. Ertel, J. Bárta, et al., "The analysis of properties and forming of laser welded superduplex steel SAF 2507," Hutnik-WH, 82, No. 9, 627-631 (2015).

6. A. K. Sinha, D. Y. Kim, and D. Ceglarek, "Correlation analysis of the variation of weld seam and tensile strength in laser welding galvanized steel," Opt. Laser Eng., 51, 1143-1152 (2013).

7. W. Fratz, F. Stachowitz, T. Trzepiecinski, and T. Pieja, "Forming limit of the heat resistant AMS 5599 sheet metal," Hutnik-WH, 81, No. 7, 442-445 (2014).

8. Z. Q. Zhang, X. F. Jia, Y. J. Wang, and P. Gao, "Optimization analysis of initial sheet metal contour line for high-strength boron steel in hot stamping," Strength Mater., 48, No. 1, 77-81 (2016).

9. A. Khan, V. V. N. Satya Suresh, and S. P. Regalla, "Effect of thickness ratio on weld line displacement in deep drawing of aluminium steel tailor welded blanks," Proc. Mat. Sci., 6, 401-408 (2014).

10. J. Slota, M. Jurčišin, and E. Spišák, "Experimental and numerical analysis of local mechanical properties of drawn part," Key Eng. Mater., 586, 245-248 (2014).

11. Y. Morishita, T. Kado, S. Abe, et al., "Role of counterpunch for square-cup drawing of tailored blank composed of thick/thin sheets," J. Mater. Process. Tech., 212, 2102-2108 (2012).

12. J. Moravec, "Magnetic field application in area sheet metal forming," in: Proc. of the 25th Anniversary Int. Conf on Metallurgy and Materials (METAL 2016, May 25-27, 2016, Brno), TANGER Ltd., Ostrava (2016), pp. 303-309.

13. V. V. N. Satya Suresh, S. P. Regalla, A. K. Gupta, and G. Padmanabham, "Weld line shift in the case of tailor welded blanks subjected to differential strengths with respect to TIG and laser welding," Mater. Today - Proc., 2, 3501-3510 (2015). 